Article

\title{
Why Is Ownership an Issue? Exploring Factors That Determine Public Acceptance of Product-Service Systems
}

\author{
Catherine E. Cherry * (1) and Nick F. Pidgeon \\ Tower Building, School of Psychology, Cardiff University, Cardiff CF10 3AT, UK; pidgeonn@cardiff.ac.uk \\ * Correspondence: cherryce@cardiff.ac.uk
}

Received: 14 May 2018; Accepted: 13 June 2018; Published: 2 July 2018

check for updates

\begin{abstract}
Shifting away from ownership towards access-based consumption, innovative new business models known as product-service systems (PSS) are advocated as part of a more circular, resource efficient economy. With product ownership (and responsibility for repair) remaining with providers, pay-per-use services are promoted as one such model, which can both increase product longevity and reduce the 'burdens of ownership' on consumers. However, PSS also require public acceptance of access-based consumption, including the long-term use of non-owned products and a range of accompanying contractual obligations. We conducted a series of deliberative workshops with the public, aiming to explore the concept of pay-per-use PSS and the role that concerns about ownership and responsibility may have in determining public acceptance. Rather than focusing on innate desires for product ownership, we found that participants' concerns regarding pay-per-use PSS were usually related to wider fears surrounding the risks and responsibilities of entering into contract-based service agreements. Identifying four public narratives of service provision (Ownership and convenience; Risk and responsibility; Affordability and security; Care and control), we argue that successful introduction of PSS will only be possible if careful consideration is given to deeply held values pertaining to ownership, responsibility and trust that influence such cultural understandings.
\end{abstract}

Keywords: circular economy; product-service systems; public acceptance; alternative ownership models; responsibility; ownership

\section{Introduction}

With unsustainable patterns of production and consumption now understood to be a major cause of modern global environmental challenges [1], the concept of the circular economy has gathered increasing interest over recent years as a solution to issues such as climate change, waste and resource depletion. Rising up the policy and business agenda [2,3], advocates of the circular economy describe the need to shift away from the current linear 'take-make-dispose' economy towards a circular economy that is designed to keep products and materials circulating for as long as possible, before recovering them for future use [4]. Going beyond existing conceptualisations of recycling, a series of closed material loops is proposed, aiming to increase product longevity and reduce waste through: product repair and maintenance; re-use and redistribution of products; and refurbishment and remanufacturing schemes $[4,5]$. In order to facilitate such a social and economic transformation, innovation will be needed to redesign both products, services and the business models by which they are produced and sold $[6,7]$.

One strategy currently being proposed as a step towards a circular economy relies on servitisation, where innovative business models support the dematerialisation of the economy and shift towards a focus on selling services rather than products alone. Also labelled eco-efficient services and sustainable-home services, such product-service systems (PSS) can broadly be understood as 'integrated bundles of products and services which aim at creating customer utility and generating 
value' $[8,9]$, although due the wide range of business models incorporated within the concept of PSS, there is no one single definition. Tukker defines three main categories of PSS within which innovative business models can be classified [10]. Most similar to current business models, Product-oriented services sell additional services alongside products, such as extended/lifetime warranties and maintenance services. Use-oriented services are designed to provide access to products and can include the leasing, renting and pooling of products, the ownership of which remains with the service provider. Finally, the most radical category, Results-oriented services include home service provision agreements or contracts for the delivery of functional results, with no pre-determined products involved.

A key feature of both Use-oriented and Results-oriented services is a shift away from current forms of ownership-based consumption, with product ownership remaining with producers or service providers. Building on Stahel's [11] vision of a functional economy, these forms of PSS are based on the premise that "the economic objective of the functional economy is to create the highest use value for the longest possible time while consuming as few material resources and energy as possible" (p. 91), thus optimising the use and distribution of products within society. Common examples of business-to-consumer Use-oriented services include car sharing schemes, as well as corporate example of peer-to-peer accommodation sharing (Airbnb), whilst other models, such as the idea of library of things (where individuals can borrow everyday items such as tools or kitchen appliances) are currently more niche. However, examples of the most innovative business models mainly exist within business-to-business markets [12]. These Results-oriented services include examples such as Rolls Royce's aircraft service package "Power-by-the-Hour" for engine repair and remanufacture and Phillip's pay-per-lux model of lighting services. However, some innovative examples of business-to-consumer PSS are beginning to become available in the form of pay-per-use contracts for home service provision (see Section 3 for details of Riversimple [13] and Bundles [14] — two companies that provide the service of transport and washing direct to households).

At this stage it is important to briefly note that as yet the environmental benefits of such schemes is yet to be demonstrated empirically in most cases. Findings from existing studies surrounding Use-oriented services tend to highlight mixed results, with the true sustainability of PSS dependent on a range of complex factors [15,16]. Using car sharing as an example, Martin and Shaheen [17] demonstrate that although some service users reduced their car use dramatically, others in fact increased their carbon footprint due to the increased access to a vehicle. There are also issues regarding the possibility of rebound effects [15] occurring due to a range of mechanisms, including whether an increased availability of services (such as transport) leads to an increase in overall use, as well as whether any money saved through using PSS is spent on other carbon intensive products. These concerns lead Tukker $[8,10]$ to conclude that only the most radical PSS (Results-oriented services based on achieving functional results, rather than Product- or Use-oriented services such as product leasing or sharing) are likely to have significant environmental benefits.

However, with future developments in mind, PSS are still advocated by many for their possible sustainability benefits. In particular, the proposed advantages of pay-per-use home service provision schemes is seen as lying in the ability to enable product management across the whole lifecycle, and thus: improve product design and material efficiency; incentivise product longevity and recyclability; and facilitate product maintenance, repair and remanufacturing [18,19]. Mont [18] highlights a range of opportunities that such PPS may offer for business, the environment and consumers. For companies, these include adding value to products, opportunities for innovation and growth, and developing business-consumer relationships; all of which could be achieved whilst still reducing resource use and waste creation. For consumers, a range of benefits to PSS have been suggested, including increased diversity and choice; maintenance and repair provisions; varied payment options; and product-service customisation. In addition, Bocken [20] highlights how such pay-per-use models may encourage more sustainable user behaviour by increasing consciousness around personal consumption levels; a theory they are currently testing through analysis of the HOMIE washing as a service business model [21]. However, concerns have also been raised that this shift in 
product ownership, and the property rights associated with this, could lead to consumer reluctance surrounding the adoption of non-ownership based PSS [22].

A number of papers have reflected on consumer acceptability of PSS, but despite often highlighting a general belief that consumers will not easily accept non-ownership based consumption [18,23], there is often an assumption that low entry barriers, due to lower costs than purchasing outright will be enough to encourage consumer uptake [10]. Only more recently have questions surrounding the role of consumers/users of these services been examined in more detail [24]. Focusing primarily on barriers to consumer acceptance and uptake of PSS, the following influences have been identified (based on $[25,26]$ ):

Price and affordability: including affordability of fixed or monthly costs; and perceptions of lifetime costs of products.

- Product-service specifics: including perceived quality of PSS; availability and convenience of services; transaction costs; safety/hygiene concerns; appropriateness of PSS to specific situation.

- Consumer characteristics: including personal habits; personal mind-set and willingness to change; risk aversion; environmental attitudes; relationships with products; and current lifestyle choices.

$\bigcirc$ Relationship with service provider: including company reputation/image; the uncertainties surrounding PSS; and the effectiveness of communications.

Based on a number of case studies of specific, and usually existing, Use-oriented services-such as car sharing schemes, product rentals and leasing of clothing and appliances-this research often suggests that generally consumers have a positive response to adopting PSS (despite specific concerns based on the factors listed above). In particular, paying only for what you use, avoiding rapid product obsolescence, seamless provision of needs, and avoiding obligations for product maintenance and repair, are all seen as positive aspects of access over ownership based provision [27].

However, to date, very little research has directly explored consumer perceptions, motivations or concerns surrounding non-ownership based PSS that make use of pay-per-use home service provision based business models (i.e., Results-oriented services). In addition, whilst research into consumer perspectives surrounding participation in PSS is growing, this literature has focused primarily on the concerns and motivations of those individuals who are already making use of such services. As such, these studies are also usually case study specific, with relatively little currently known about the acceptance of these new business models within the wider public. Both willing and able to engage in complex debate surrounding energy futures and sustainability [28], we argue that the wider public should have a voice in the debate surrounding the transition towards a more circular, resource efficient economy and the future business models that may develop within it, both as future users and more broadly as citizens. As such, although evidence from case studies can be very effective in investigating the motivations and concerns of individuals participating in specific PSS, the wider perceptions and meanings surrounding the broader concept of PSS that may be evoked are less likely to be fully explored. Given recent calls for the development, promotion and adoption of non-ownership based PSS, there is thus an urgent need for research that explicitly explores the concept of Results-oriented services and how these new business models may be perceived.

In this paper, we aim to address this gap, using deliberative methods to explore the concept of the pay-per-use home service provision with members of the public. Our aim is to contribute to existing literature in three main ways: (1) to specifically explore the factors that influence public perceptions and concerns surrounding Results-oriented services; (2) to reflect on how attempts to mainstream these PSS are likely to be received by the wider public; and (3) to highlight the implications of our findings for the policy/business agenda in relation to the successful development and adoption of business-to-consumer PSS. Highlighting debates within the academic literature, we first provide a brief overview of the importance of product ownership, property rights and object-self relations in relation to non-ownership based consumption. Section 3 then provides a detailed description of the methods adopted within the research, before Section 4 goes on to illustrate our key findings, detailing the three 
narratives of concern that arose within the public discussion surrounding PSS. Placing our findings in context, we end with a discussion based on our outlined research questions and consider the role that PSS may play in transitioning towards a more circular, resource efficient future and the importance of addressing public concerns if these aims are to be achieved.

\section{Ownership, Responsibility and PSS}

Displaying distinctly different characteristics to ownership, the advantages of access-based consumption are mainly seen to be derived from the non-ownership based nature of these business models [29]. However, ownership is often seen as providing intangible added value [8], leading many to raise concerns regarding the possibilities of large-scale adoption $[18,22]$. A key element of this debate surrounds the rights and responsibilities that come with property ownership. Four types of property rights have been identified [30,31], including the right to: (a) use property; (b) retain any benefits from using property; (c) modify or alter property; and d) transfer the ownership of property. By regulating both the incentives and behaviours associated with products, these rights provide the owner with freedom and control to use and enjoy the product as they see fit, as well as a strong sense of identification with the product [30,32]. Seen through this lens, access-based consumption requires acceptance of a reduced set of property rights.

Whilst product ownership, and thus the right to (c) modify and (d) transfer ownership of the product remain with the service provider, Use-oriented PSS, such as renting, leasing and sharing, provide service users' with the right to both (a) use products and (b) retain the benefit from product use (usually over a set period of time). By focusing on the provision of results and pay-per-use home service provision, property rights retained when using Results-oriented PSS may be even more restricted, due to contractual clauses relating to the frequency or duration of product use. Conversely however, such property rights also come with responsibilities attached. These 'burdens of ownership' take the form of a range of risks and responsibilities [30,33], including the risks of incorrect product selection and product obsolescence and the responsibility for product management, maintenance and repair. By relieving these risks and responsibilities, access-based consumption and PSS may become increasingly attractive, despite the sacrifice of full property rights.

Another important difference between ownership and access-based consumption is in the nature of the relations they engender between products and their users [32], with Chen [34] (p. 926) proposing that access-based consumption 'could permit consumers to establish other kinds of relationships with the objects, thereby mediating or reducing the need to possess'. For example, relationships with products could be functional or utilitarian, aesthetic or experiential, intimate or distant. The extent and direction to which these relationship develop has not yet been explored within the wider research, however, Bardhi \& Eckhart [32] conceptualise six dimensions of access-based consumption by which these relationships can be understood:

1. temporality, ranging from short- to long-term access to products;

2. anonymity, based on the type and level of interpersonal relationships required;

3. market mediation, ranging from profit-driven business models to non-profit organisations;

4. consumer involvement, in terms of the level of effort and communication required;

5. type of product accessed, i.e., functional vs. experiential or material vs. digital; and

6. political consumerism, relating to the extent to which participation is an ideological choice.

Using this framework as a basis for examining the motivations for participating in the car sharing scheme Zipcar, Bardhi \& Eckhart [32] investigated the importance of what they term object-self relations. With possessions recognised as an important way in which identity is expressed, often becoming part of an extended-self [35], one aspect of their study explored what form of relationships between service users and their shared car may develop under an access-based model. Supporting theories that an access-based 'market can liberate consumers from the emotional, social and property obligations that come with ownership' (p. 895), they found participant's adopted a primarily utilitarian relationship 
and did not display any perceived sense of ownership over the cars they shared, with motivations based primarily on a desire for a cheap and easy form of transport.

Another important aspect of such object-self relations is the ethics of care that accompany them (cf., [36,37] which highlight the sense of responsibility for products and second-hand exchange). The idea that individuals will take less care when using products that are accessed rather than owned is a common concern surrounding access-based consumption [19,27,32]. Discussing the effectiveness of PSS, Tukker [38] highlights how, despite generally being seen as positive motivation for participation in PSS, the reduced cost of product access through renting and leasing (Use-oriented services) may actually lead to negative outcomes, with product lifetimes shortened due to user carelessness. In contrast, Results-oriented services may offer more promise in this area, possibly acting to make users more careful, both in terms of product care and in through more conscious and careful use and management, due to the contractual agreements required within pay-per-use home service provision.

Recently, claims have been made that consumers are increasingly valuing experience over utility [39] and that desires for experiential, current and eco-friendly products are leading to an upsurge in demand for access-based consumption [30]. However, despite growing interest in access-based consumption, the importance and value of ownership throughout the wider public is repeatedly highlighted, with such schemes currently remaining relatively niche $[27,30,32]$. As such the idea that wider public preferences may be shifting towards access over ownership cannot be assumed [40]. Highlighting the need for further research into the relationship between ownership and access-based consumption models, Lovelock \& Gummesson's [29] calls for specific research into perceptions of non-ownership based consumption have gone largely unheeded (with only a few notable exceptions [27,32]). Recognising the partially context specific nature of the research into car sharing PSS, Bardhi \& Eckhart [32] call for other models of access-based consumption to receive increased academic attention. Addressing these gaps, our paper will explore the factors that influence public acceptance of pay-per-use Results-oriented services.

\section{Materials and Methods}

Building on established methodological techniques for exploring public engagement with, and acceptability of, different science and technology issues [28,41], a bespoke method for exploring the public acceptability of alternative systems of production and consumption was developed. A series of deliberative workshops were designed, aiming to elicit public perceptions and values surrounding PSS. The workshops were broadly framed around the idea of exploring the future of consumption, utilising deliberative techniques to focus first on past trends in consumption across society, before asking participants to consider how their personal patterns of consumption have changed over time. Following this, participants took part in World Café style group discussions [42] to explore alternative consumption practices. This activity was designed to encourage participants to engage with the wider concepts involved (e.g., specific PSS), as well as provide context for participants to be able to imagine the implications for their own lives of each scenario. Scenario materials took two separate forms: (1) vignettes, or 'a day in your life' stories that provided a narrative vision of the future of everyday life-presented and deliberated in small group format (3-5 participants); and (2) posters that provided further details of products and services available within them-presented and discussed in full group format (11-13 participants).

In order to increase participant engagement, the activities and materials were not designed using the language of PSS explicitly, instead constructed using accessible language and specific examples of product-service systems that are now or may become available. Titled Rethinking Ownership, the scenario was based on three examples of pay-per-use Results-oriented PSS. Two key examples were given: (1) a pay-per-use washing service, based on Bundles, a Dutch service that for a monthly fee provides washing machine installation of machine (with usage restrictions), detergent, maintenance and remanufacturing [14]; (2) a pay-per-use transport service, based on Riversimple, an innovative British company that is trialling an inclusive mobility service that includes car lease 
and use (with mileage restrictions), fuel, MOT, servicing, repair and insurance [13]. In both examples, the company maintains ownership of the product, despite its remaining within the home for an extended period of time. Both companies also make use of contractual service agreements in which householders choose from a range of pricing plans, each of which provides them with a different level of product usage (i.e., washes or miles). The possibility of this form of business model spreading to other products in the home, such as electronic and kitchen appliances, as well as furniture provision, were also discussed.

Two workshops were held in Cardiff and two in Bristol, with each city hosting one group of higher income participants (socio-economic classification $\mathrm{ABC} 1$ ) and one group of lower income participants (socio-economic classification C2DE). In total, 51 participants were recruited using a professional external recruitment agency, who were tasked with recruiting a diverse (but not representative) sample of participants from a range backgrounds, based on age, gender and socio-economic classification (see Table 1 for a demographic breakdown of participants).

Table 1. Demographic profile of participants.

\begin{tabular}{|c|c|c|c|c|c|}
\hline & $\begin{array}{l}\text { Demographic } \\
\text { Classification }\end{array}$ & $\begin{array}{c}\text { No. } \\
\text { Participants }\end{array}$ & & $\begin{array}{l}\text { Demographic } \\
\text { Classification }\end{array}$ & $\begin{array}{c}\text { No. } \\
\text { Participants }\end{array}$ \\
\hline \multirow{2}{*}{ Gender profile } & Women & 27 & \multirow{6}{*}{$\begin{array}{l}\text { Socio-economic } \\
\text { classification }\end{array}$} & $\mathrm{A}$ & 0 \\
\hline & Men & 26 & & $\mathrm{~B}$ & 12 \\
\hline \multirow{6}{*}{ Age profile } & $20-29$ & 12 & & $\mathrm{C} 1$ & 17 \\
\hline & $30-39$ & 8 & & $\mathrm{C} 2$ & 8 \\
\hline & $40-49$ & 8 & & $\mathrm{D}$ & 6 \\
\hline & $50-59$ & 7 & & $\mathrm{E}$ & 10 \\
\hline & $60-69$ & 8 & \multirow{2}{*}{ Location } & Cardiff & 24 \\
\hline & $70+$ & 8 & & Bristol & 27 \\
\hline
\end{tabular}

Anonymised transcripts were produced from audio-recordings of each workshop activity. This generated a large qualitative data set, requiring careful comparative analysis of the data across all workshops. Analytical focus was placed on revealing the substantive ways in which people describe, understand and evaluate the concept of pay-per-use home service provision, and the trade-offs and conditions they are (un)willing to accept. The qualitative analysis package NVivo was used to conduct an interpretive qualitative analysis of the data. Based on grounded theory [43-46], the analytical process followed these steps. Starting with open-coding of the data set, a series of both descriptive and theoretical categories were identified to produce a grounded (rather than pre-prescribed) coding framework. An iterative process of constant checking and comparison between codes was conducted, making sure there was a 'good fit' between data and codes. Codes were then (re)grouped into meta-codes to allow targeted rereading of the data to consider and then describe the broader empirically and theoretically relevant outcomes of the analysis.

\section{Emerging Narratives of Service Provision}

Many of the previously identified motivations and conditions for participation in PSS were echoed within participant discussions (e.g., concerns surrounding the direct costs of pay-per-use home service provision vs. owning). However, the use of a qualitative and deliberative methodology allowed for a richer discourse to emerge surrounding the ways in which participants made sense of pay-per-use home service provision and imagined the possibilities of adopting these in the future. Four narratives arose across the different groups, highlighting key areas of concern and approval surrounding the concept. Ownership and convenience discussed the trade-off between ownership property rights and the convenience that pay-per-use home service provision could provide. In contrast, Risk and responsibility and Affordability and security raised strong concerns around the risks of accepting the contractual obligations required within Results-oriented PSS. Finally, Care and control grew out 
of concerns surrounding the implications of new relationships with non-owned products that may develop under a pay-per-use service provision system.

\subsection{Ownership and Convenience}

The first narrative took the form of debate surrounding the benefits of property ownership vs. a general desire for convenience. An intrinsic desire for ownership was often evident, both individually and as a widespread social norm:

I always liked the idea that I own something you know. [ ... ] I grew up with that kind of idea that you earn the money and when you got the money, you buy it, you own it you know. (Pete, B1)

I think it works in certain scenarios for certain objects. But I think for a lot of people in a lot of objects, they want to feel like, "I bought this" you know, "I paid for this. That's mine." [ ... ] I think ownership is quite an important identity for a lot of people. [...] So when they can't be owning something, they'll feel a bit of dissatisfaction. I think a lot of people would feel dissatisfaction. (Hannah, C1)

These feelings were based on a range of factors, including personal histories, identity and status, which for some participants strongly outweighed any benefits of non-ownership based service provision. In contrast, a small number of participants displayed a more flexible desire for ownership, identifying positive (usually convenience-based) benefits of pay-per-use home service provision and thus remaining largely in favour of adoption:

In principle, this for me, this idea of having most things on a rental basis, but that you can be assured it's going to work the whole time, or like have very little down time if it doesn't because you always got someone that's coming to fix it or replace a bit, or replace it, is good. I would like that for most things, I think. (Arnie, B1)

More common was a more nuanced position, based on a differentiation between product types and circumstances, and understanding service provision as a trade-off between the benefits of ownership and a desire for convenience. For more personal items, such as clothing and furnishings, the benefits of ownership of were more commonly appreciated, usually due to strong connections between these items and personal identity; for some participants this was also true of cars, connected as they often are to status and identity, as well as providing pleasure and enjoyment (cf. [47]). Whereas for more functional items (usually appliances and tools) the convenience of non-ownership were strongly appreciated:

Well, like initially, I was a bit like I don't know just like instinctively like I would rather own the stuff than be renting it. But then I thought about it. And I, why would I care about that? It's just, this seems like a much better system like as you said who cares if they own a washing machine if you can just pay 15 quid a month and you get all that stuff included. (Mark, B2)

And I suppose for some people the transport is kind of like having a car, like your car, you know, maintain it. That is his enjoyment. So it's kind of, but I imagine for many people being like, "No, you don't have to worry about it. I've got too much to do anyway." (Katie, B2)

Where participants' initial reactions were positive, they tended to coalesce around existing experiences of product malfunction and the costs of repair, with approval often stemming largely from a desire to reduce their personal responsibility for product maintenance (cf. [32]). For some the main benefit was seen to be the reduction in the time and effort spent dealing with such eventualities, whilst for others it was the reduced anxiety of knowing that any problems would be dealt with efficiently:

But the idea of responsibility being on someone else to manage and maintain [products], I quite like that. (Pete, B1) 
The responsibility is all with the company and that'd be a refreshing thing, wouldn't it somehow? (Jake, C1)

So if it broke, somebody comes tomorrow. That peace of mind that I knew if it broke today, they'd come tomorrow. (Sally, C2)

However, this desire for convenience led to concerns surrounding the risks of expecting highly efficient and reliable services and suggestions that trust in service providers would be a highly influential factor determining uptake:

I suppose, it could be great, couldn't it? It could be efficient if the table breaks and you've got a new one within an hour, because it's the company that does it all the time, day in, day out. And you couldn't have done it on your own that quickly. So, it could be really good. But if you get a company that's not good. [ ... ] You rely on other people. You're heavily reliant on how good and how responsive they are. (Mia, B2)

\subsection{Risks and Responsibility}

The second narrative primarily surrounded concerns about the reliance of pay-per-use service provision on contracts and the financial risks these may entail. The need to enter into (possible multiple) contracts for the provision of different products and services within the home, was seen as a step too far for many participants, leading to serious concerns surrounding adoption of such business models, and even outright rejection of the PSS concept. These concerns often related to a strong distrust in business that pervaded wider discourses around current consumption systems, as well as discussions of specific PSS. In part these responses built on personal experiences and the current contractual obligations of participants, and some participants had trouble getting to grips with the details of pay-per-use home service provision (cf. [25]). Often relying on the examples of hire-purchase cars and mobile phone contracts, participants extrapolated possible future relationships and practice based on past knowledge and experience, culminating in widespread concern surrounding the small-print and/or loop-holes that they believed may purposefully be designed into such contracts:

I would be worried in this scenario what the catch is going to be because they're always there. I don't care whether it's your washing machine, your television, once you go into those type of contracts and it's not your own, there is always some sort of penalty that's hid away. [ ... ] They're not going to give you a $£ 50,000$ car and you return them a wreck worth $£ 10,000$. Do you understand? (Ralph, B1)

I think there'd be more contractual issues with an item that you're leasing because it's still theirs. And they'll be like, "Well you must've overfilled that washing machine. You must have put your kitten in there or something" you know what I mean? "That's why it's not working". (Hannah, C1)

As Ralph and Hannah's comments highlight, this distrust in business and contracts tainted perceptions of pay-per-use service provision. Even when participants were aware that such contracts would include the provision of full product repair and maintenance services, they found it difficult to foresee a situation in which they were not, both financially and legally, personally responsible for product condition. This anxiety led to strong concerns around the distribution of responsibility within these business models, and participants imagined multiple circumstances through which products were accidentally damaged, believing they would be charged or penalised financially for this:

I think I like the idea of this in a way [Pause] like dealing with everything. You know, the insulation, the service, the repair, the water, even the detergent is included. And I could see it being a very appealing thing to people, especially mums and families, but I don't like the idea of contracts and being tied into something and yeah, there being like there's always loopholes, so God forbid if your kid draws on the washing machine, do they still replace it? [Laughter] So that kind of stuff, I don't really like. (Phoebe, B1) 


\subsection{Affordability and Security}

In addition to a desire to maintain a clear distribution of responsibilities, preferences for product ownership over service provision were also evident in wider concerns surrounding minimising financial risk. Phoebe's remarks above also highlight a third narrative through which contracts were often considered risky: financial lock-in. Participants highlighted the precarious nature of everyday life, raising concerns surrounding what would happen if it was no longer possible to pay service charges due to unpredictable personal circumstances, such as ill health or redundancy:

Like with the subscription model like, I would be a bit wary of signing up to so many things. Because I've been in this situation before where I've got myself like in the phone contract or something and then finding myself out of work and then having to continue paying all these things. (Mark, B1)

I think there would be an effect, in terms of financial stability [... ] If they lose their job in the next few days, then, something like, "I've got to give my washing machine back. I've got to give my car back. I've got to give all this stuff back to the place that I'm borrowing it, because I can't afford to rent anymore. But if I owned this stuff, it's kind of having money to then, okay. Well, I've got this bit of security. So, if I lose my job or something happens, then, I've got that." I don't know what the effects would be. But would you have to have more job security or lower unemployment because of this? I don't know. (Alfie, B2)

Quoting the high levels of anxiety that such financial uncertainty would bring, many participants questioned the long-term financial sustainability of such services. Two possible ways of managing this risk were suggested. For some, this situation required a personal financial buffer, in terms of increased disposable income and/or savings, leading to suggestions that this form of pay-per-use service provision may only be suitable for those with enough income and security to mitigate such risks. For others, insurance based protection would be essential, with participant's accepting that they may have to make higher monthly payments to reduce these financial risks:

If I want to avoid the risk of a bill, unexpectedly, then, I pay more, because presumably, there's options about how you lease them, what's included and what's not included. And then, it's a bit like insurance. It's all-encompassing. So, you pay the highest whack but then that covers me for everything. So, it's about how risk averse am I and how much do I want fixing, or variable in terms of mortgages.

(Mia, B2)

\subsection{Care and Control}

The final narrative emerged surrounding the new relationships pay-per-use service provision might engender between individuals and the products in their homes, and the implications these could have for everyday life. One way in which these concerns manifested was through a focus on the possibility that such services would require shifts in the way products were used in the home, such as where previously unrestricted product use is then restricted by contractual agreement (e.g., price plans that only allow use of the washing machine a set number of times per week). The possibility of managing daily life differently was controversial. Some participants imagined they would take these changes in their stride:

I agree with that. [ ... ] It's because then you can budget better. You know what you're going to buy, I'm good at budgeting. (Carole, B1)

However, highlighting the unpredictable nature of modern life and a desire for spontaneity and freedom, others found such restrictions a source of consternation and an unacceptable invasion into personal choice and control surrounding product use in the home: 
It's okay if you're the type of person that can measure what they're going to do every day of the week, I can't. Well I'm not prepared to pay for something I'm not going to use. I would prefer to pay as I go, you know. [ ... ] And then you know, and I can't measure how many gallons of petrol I'm going to use this week. I can't measure how many times I'm going to want to wash a jumper because I spilt red wine over it. You know? I just can't do it. (Ralph, B1)

Partially related to concerns around the distribution of responsibility for product condition, a second set of concerns arose around a sense of disquiet about the new relations of care that might be required when product ownership remained with service providers. Adding a more complex perspective to previous claims, there was a distinct split amongst participants regarding whether the lack of product ownership would lead to increased or decreased care for product condition:

And do you automatically then take better care of them or does it become more...? I think I would take more care of it. (Katie, B2)

I think I would definitely take a lot less care of it [Laughter]. Like I recently got a new computer or a new laptop, it's fully covered by insurance. And I'm just so risky with it because I know whatever happens to it, they can just get it fixed. [Laughter]. (Mark, B2)

However, in some cases these concerns ran much deeper, with the shift in object-self relations perceived as a threat to the use and enjoyment of products:

I suppose I'm not yet comfortable with that. I quite like the fact that I own my things, and therefore I can do whatever I, within legal reason, do whatever I like with them. I can drive my car in a way that I feel like I want to drive. And I can eat in my car if I fancied it. If I'm paying someone else can I do that? Have I got to vacuum it out every weekend. Do I have to think, you know. I suppose it's those sorts of things. I'm responsible to someone else and my actions, in my home, if it becomes my home, my furniture [... ]. If someone comes around and they have a glass of red wine and they drop it on my sofa, argh, you know. Suddenly I don't want anyone coming around. Because what if they drop it, I'm responsible because it's not mine. (Mia, B2)

The strongest reaction came from Mia, who imagining high levels of anxiety, associated PSS with a stressful imperative to maintain product quality and condition. This account goes further than previous concerns surrounding the financial implications of product damage, highlighting the repercussions such circumstances could have on personal behaviour and emotional wellbeing. As well as creating a feeling of being unable to relax and enjoy the use of these products within the home, there was also the possibility that this form of product provision may impact on personal relationships with family and friends. Preferences for product ownership were thus often based on achieving a sense of choice and control surrounding product use, reducing anxiety and maintaining current practices and relationships in the home.

\section{Discussion: Research Implications, Limitations and Future Directions}

A shift towards a more circular, resource efficient economy will require the development of a range of innovative new business models, such as product-service systems (PSS), which aim to move away from ownership-based consumption towards the provision of services. However, research surrounding how the UK public may react to the mainstreaming of such innovative business models has so far focused almost exclusively on Use-oriented services, such as car sharing and product rental. Despite some similarities to renting and leasing schemes, pay-per-use Results-oriented services differ significantly from Use-oriented services. These differences relate to: (a) the length of time unowned products remain with the user; (b) the reliance on contractual obligations to define new distributions of responsibility for such products; and (c) the implications this has for the nature of the relationship between consumers and service providers. 
Aiming to explore these differences, we made use of deliberative methods to explore the concept of pay-per-use home service provision with members of the public. Whilst some participants did highlight an innate desire for ownership, we found that on the surface at least, many participants were both interested in and positively predisposed towards the concept of non-ownership based consumption. Partially supporting claims that PSS would reduce the 'burdens of ownership' on consumers, by reducing the risks of inappropriate product choice and repair and maintenance costs [30], participants from a range of different backgrounds highlighted the potential for such services to increase convenience and reduce worries over product breakdown and repair. However, by digging deeper into the implications of pay-per-use service provision for everyday life, four narratives of concern emerged that led even those who were positively predisposed to access-based consumption to prefer existing models of ownership-based consumption.

The risks posed from entering into contractual agreements with service providers proved to be the main source of anxiety for most participants. Whether in relation to the fear of being financially locked in to contracts that may become unaffordable or concerns regarding the new distribution of responsibility for product condition, there was a general reticence to enter into service agreements, which was often linked to a strong distrust in business. Beyond this, the new relationships of product care and control that participants imagined in response to the long-term possession of non-owned products in the home were also a source of anxiety. As such, it was not the loss of property rights (i.e., the right to use, benefit from, modify or sell property $[30,31]$ ) per se that concerned people, but the loss of the wider sense of flexibility, autonomy and control that comes with ownership. For many, this is likely to be in part because it is the practices (mobility, communication, food preparation) that are valued, rather than the objects that provide those services (cars, phones, kitchen appliances) [48]; as such, the emotional attachments to the material objects remain, despite the lack of personal responsibility and ownership.

Advocated as a way to increase producer responsibility for the products they manufacture and sell, much of the literature around access-based consumption works on the assumption that by removing the responsibility for product maintenance, repair and replacement, such services will be viewed as more convenient than traditional ownership. However, whilst this claim may be partly or wholly true in relation to Use-oriented services such as car sharing and product rental, it is clear that in the case of pay-per-use home service provision the opposite occurs, with participants experiencing a sense of anxiety surrounding a perceived increase in personal product responsibility. These concerns led many to suggest they would be more, rather than less careful with the unowned products in the home, contrasting and complicating assumptions made within the literature $[19,27,32,38]$.

These findings have a number of implications for business and policy makers trying to develop and mainstream Results-oriented PSS. As we have demonstrated, whilst participants were positive about the concept of such services, worries surrounding contractual obligations and the distribution of product responsibility dominated public narratives of concern, leading many to reject the concept outright. Although access-based contracts for digital services are becoming increasingly common, mainstreaming pay-per-use home service provision for physical products may be more difficult. Interestingly, this may be more, rather than less true for functional products, where long lifetime and relative lack of connection to personal identity and experience (e.g., in comparison to mobile phones) mean that a drive for luxury and up-to-date products is likely to be lacking. As such, particular care will need to be given to the development of fair and flexible contracts in which the rights and responsibilities of both service providers and service users are clearly defined.

Whilst companies developing pay-per-use PSS for functional items (e.g., washing machines or other household appliances) may assume that consumers will primarily develop utilitarian relationships with non-owned products in their homes (cf., Bardhi \& Eckhart's findings surrounding service user's utilitarian relationships with shared cars [32]), our findings suggest this may not always be the case. Although participant's tendency to describe the relationships of care that would be required to ensure the good condition of unowned products may be perceived as a positive indication 
of careful product use by consumers, the high levels of anxiety connected to such care may in fact deter public uptake of such service-based business models. For pay-per-use service provision to be successful, businesses will need to consider such public preferences and concerns and be guided by values of trust, flexibility and responsibility when developing pay-per-use, Results-oriented business models, as well as emphasising these aspects within their wider discourse and communications.

Despite the benefits of exploring the concept of pay-per-use home service provision with the wider public, our research also has a number of limitations that point to areas of further research. Firstly, due to the need for deep discussion with participants, our research was restricted to two case site cities (Cardiff and Bristol, which geographically are located in relatively close proximity). As such, it will also be important for further work to consider the wider social and cultural conditions that determine preferences for PSS and identify whether the narratives identified here are common across the UK, Europe and further afield. The second limitation relates to the importance of context. The main aim of our research was to take a step back and consider the concept and process of Results-oriented services more widely with members of the public. However, in practice the contexts surrounding these acceptability of novel pay-per-use home service provision models will of course depend on the type of product/service that is being delivered (cf. [49]), and further research exploring how each narrative of concern relates to different product types would be useful.

Finally, and we believe most importantly, another limitation lies in our inability to comment on whether these perceived concerns would materialise if such innovative business models were made available in the UK. As Results-oriented services continue to be developed, we would recommend conducting similar research exploring such business models in different contexts and with both service users and the general public. The aim should be not only to identify the characteristic features of PSS that led to public and user acceptance, but to longitudinally explore how these perceptions change over time. For example, it would be interesting to see whether the anxieties and concerns (surrounding the contractual aspects of pay-per-use home service provision) imagined by our participants actually materialised, (1) when full details and branding of existing business models is provided; and (2) after using such services for a period of time. Following the example of Bocken et al.'s HOMIE study [21], further case-based research that takes into account both context specific and wider narratives of concerns will be required if novel, sustainable and publicly acceptable pay-per-use home services are be developed.

\section{Conclusions}

In conclusion, pay-per-use home service provision represents a distinct form of access-based consumption, both theoretically and contextually distinct from other forms of access (such as car sharing [27,32] or product rental [26,30]). Whilst all access-based consumption challenges traditional concepts of product ownership, in comparison to sharing or renting pay-per-use service provision requires the acceptance of a different set of business model characteristics, including the long-term possession and use of unowned products in the home, and the range of contractual obligations that accompany this. Whilst an intrinsic desire for ownership is often cited as a key reason for public dissatisfaction with PSS, our findings have highlighted how a desire for ownership was often more related to fears relating to the distribution of responsibility and the potential for financial lock-in to unsustainable contractual payments. Interestingly, these findings are somewhat counter intuitive, as pay-per-use Results-oriented PSS are often advocated as less radical than Use-oriented PSS due to the constant product access facilitated by sole and ongoing possession of products, and thus arguably, more similar to current ownership-based consumption.

By exploring public discourses surrounding the possibilities for transitioning towards access-based consumption and the new business models (such as pay-per-use home service provision) this may require, we have identified a range of concerns and conditions that will need to be addressed if such a transition is to be successful. We believe that cultural understandings of ownership will be crucial in understanding the possibilities for any large-scale transition towards sustainable 
consumption. As such, the successful introduction of PSS will only be possible if careful consideration is given, not only to factors such as price and convenience, but also to deeply held values pertaining to trust and responsibility that influence these cultural understandings. The challenge for businesses will be in developing new and innovative business models that engage with and address such public concerns, and in testing them with both general and specific publics to improve the possibility of successful public uptake.

Author Contributions: Conceptualization, C.E.C. and N.F.P.; Methodology, C.E.C. and N.F.P; Formal Analysis, C.E.C.; Writing-Original Draft Preparation, C.E.C.; Writing-Review \& Editing, C.E.C. and N.F.P.; Project Administration, C.E.C. and N.F.P.; Funding Acquisition, N.F.P.

Funding: This research was supported by an RCUK grant: EPSRC-EP/M008053/1.

Acknowledgments: We would like to thank our CIE-MAP colleagues and partners Green Alliance, whose input and advice has been invaluable throughout the development of this research project. Given the nature of the data collected, the data supporting this paper cannot be made available. This is because, at the time of collection, participant consent to archive the data was not obtained.

Conflicts of Interest: The authors declare no conflicts of interest.

\section{References}

1. United Nations. Agenda 21. In Proceedings of the United Nations Conference on Environment \& Development, Rio de Janerio, Brazil, 3-14 June 1992.

2. Walport, M.; Boyd, I. From Waste to Resource Productivity Report of the Government Chief Scientific Adviser; Government Office for Science: London, UK, 2017.

3. European Commission. Closing the Loop-An eu Action Plan for the Circular Economy; European Commission: Brussles, Belgium, 2015.

4. Ellen MacArther Foundation. Towards the Circular Economy, Economic and Business Rationale for an Accelerated Transition; Ellen MacArthur Foundation: Cowes, UK, 2013.

5. Benton, D.; Hazell, J.; Hill, J. The Guide to the Circular Economy; Do Sustainability: London, UK, 2014.

6. Boons, F.; Montalvo, C.; Quist, J.; Wagner, M. Sustainable innovation, business models and economic performance: An overview. J. Clean. Product. 2013, 45, 1-8. [CrossRef]

7. Royal Society of the Arts. Investigating the Role of Design in the Circular Economy; RSA: London, UK, 2013.

8. Tukker, A. Product services for a resource-efficient and circular economy-A review. J. Clean. Product. 2015, 97, 76-91. [CrossRef]

9. Boehm, M.; Thomas, O. Looking beyond the rim of one's teacup: A multidisciplinary literature review of product-service systems in information systems, business management, and engineering \& design. J. Clean. Product. 2013, 51, 245-260.

10. Tukker, A. Eight types of product-Service system: Eight ways to sustainability? Experiences from suspronet. Bus. Strateg. Environ. 2004, 13, 246-260. [CrossRef]

11. Stahel, W.R. The functional economy: Cultural and organizational change. In The Industrial Green Game; National Academy Press: Washington, DC, USA, 1997; pp. 91-100.

12. Baines, T.S.; Lightfoot, H.W.; Evans, S.; Neely, A.; Greenough, R.; Peppard, J.; Roy, R.; Shehab, E.; Braganza, A.; Tiwari, A. State-of-the-art in product-service systems. Proc. Inst. Mech. Eng. Part B 2007, 221, 1543-1552. [CrossRef]

13. Riversimple. Available online: https:/ /www.Riversimple.Com/ (accessed on 30 April 2018).

14. Bundles. Available online: https://www.Bundles.Nl/en/ (accessed on 30 April 2018).

15. Schor, J. Debating the sharing economy. J. Self-Gov. Manag. Econ. 2016, 4, 7-22.

16. Zamani, B.; Sandin, G.; Peters, G.M. Life cycle assessment of clothing libraries: Can collaborative consumption reduce the environmental impact of fast fashion? J. Clean. Product. 2017, 162, 1368-1375. [CrossRef]

17. Martin, E.W.; Shaheen, S.A. Greenhouse gas emission impacts of carsharing in north america. IEEE Trans. Intell. Transp. Syst. 2011, 12, 1074-1086. [CrossRef]

18. Mont, O.K. Clarifying the concept of product-Service system. J. Clean. Product. 2002, 10, 237-245. [CrossRef] 
19. Manzini, E.; Vezzoli, C. A strategic design approach to develop sustainable product service systems: Examples taken from the 'environmentally friendly innovation'italian prize. J. Clean. Product. 2003, 11, 851-857. [CrossRef]

20. Bocken, N. Business-led sustainable consumption initiatives: Impacts and lessons learned. J. Manag. Dev. 2017, 36, 81-96. [CrossRef]

21. Bocken, N.; Bom, C.; Lemstra, H. Business experiments as an approach to drive sustainable consumption: The case of homie. Delft Univ. Technol. 2017, 8, 41-45.

22. Lebel, L.; Lorek, S. Enabling sustainable production-consumption systems. Annu. Rev. Environ. Resour. 2008, 33, 241-275. [CrossRef]

23. Schrader, U. Consumer acceptance of eco-efficient services. Greener Manag. Int. 1999, 25, 105.

24. Vezzoli, C.; Ceschin, F.; Diehl, J.C.; Kohtala, C. Why have 'sustainable product-service systems' not been widely implemented? J. Clean. Product. 2012. [CrossRef]

25. Rexfelt, O.; Hiort af Ornäs, V. Consumer acceptance of product-service systems: Designing for relative advantages and uncertainty reductions. J. Manuf. Technol. Manag. 2009, 20, 674-699. [CrossRef]

26. Antikainen, M.; Lammi, M. Consumer acceptance of novel sustainable circular services. In Proceedings of the ISPIM Conference on International Society for Professional Innovation Management (ISPIM), Porto, Portugal, 16-19 June 2016.

27. Catulli, M. What uncertainty? Further insight into why consumers might be distrustful of product service systems. J. Manuf. Technol. Manag. 2012, 23, 780-793. [CrossRef]

28. Pidgeon, N.; Demski, C.; Butler, C.; Parkhill, K.; Spence, A. Creating a national citizen engagement process for energy policy. Proc. Natl. Acad. Sci. USA 2014, 111, 13606-13613. [CrossRef] [PubMed]

29. Lovelock, C.; Gummesson, E. Whither services marketing? In search of a new paradigm and fresh perspectives. J. Serv. Res. 2004, 7, 20-41. [CrossRef]

30. Moeller, S.; Wittkowski, K. The burdens of ownership: Reasons for preferring renting. Manag. Serv. Qual. 2010, 20, 176-191. [CrossRef]

31. Furubotn, E.G.; Pejovich, S. Property rights and economic theory: A survey of recent literature. J. Econ. Lit. 1972, 10, 1137-1162.

32. Bardhi, F.; Eckhardt, G.M. Access-based consumption: The case of car sharing. J. Consum. Res. 2012, 39, 881-898. [CrossRef]

33. Berry, L.; Maricle, K.E. Consumption without ownership: Marketing opportunity for today and tomorrow. MSU Bus. Top. 1973, 21, 33-41.

34. Chen, Y. Possession and access: Consumer desires and value perceptions regarding contemporary art collection and exhibit visits. J. Consum. Res. 2008, 35, 925-940. [CrossRef]

35. Belk, R.W. Possessions and the extended self. J. Consum. Res. 1988, 15, 139-168. [CrossRef]

36. Crewe, L.; Gregson, N. Tales of the unexpected: Exploring car boot sales as marginal spaces of contemporary consumption. Trans. Inst. Br. Geogr. 1998, 23, 39-53. [CrossRef]

37. Cooper, T. Slower consumption reflections on product life spans and the "throwaway society". J. Ind. Ecol. 2005, 9, 51-67. [CrossRef]

38. Eckhardt, G.M.; Belk, R.; Devinney, T.M. Why don't consumers consume ethically? J. Consum. Behav. 2010, 9 , 426-436. [CrossRef]

39. Silverstein, M.; Fiske, N. Trading up: Why Consumers Want New Luxury Good-and How Companies Create Them; The Penguin Group: New York, NY, USA, 2005.

40. Mont, O. Drivers and barriers for shifting towards more service-oriented businesses: Analysis of the pss field and contributions from sweden. J. Sustain. Prod. Des. 2002, 2, 89-103. [CrossRef]

41. Chilvers, J.; Mcnaghten, P. The Future of Science Governance-A Review of Public Concerns, Governance and Institutional Response; Working Paper; University of East Anglia (UEA): Norwich, UK; Durham University: Durham, UK, 2011.

42. Brown, J.; Isaacs, D. The World Cafe: Shaping Our Future through Conversations that Matter; Berrett-Koehler: San Francisco, CA, USA, 2005.

43. Charmaz, K. Constructing Grounded Theory: A Practical Guide through Qualitative Analysis (Introducing Qualitative Methods Series); Sage: Thousand Oaks, CA, USA, 2006. 
44. Henwood, K.; Pidgeon, N. Grounded theory in psychological research. In Qualitative Research in Psychology: Expanding Perspectives in Methodology and Design; Camic, P.M., Rhodes, J.E., Yardley, L., Eds.; American Psychological Association: Washington, DC, USA, 2003.

45. Strauss, A.; Corbin, J.M. Grounded Theory in Practice; Sage: London, UK, 1997.

46. Glaser, B.; Strauss, A. The Discovery of Grounded Theory; Weidenfield \& Nicolson: London, UK, 1967.

47. Thomas, G.; Groves, C.; Henwood, K.; Pidgeon, N. Texturing waste: Attachment and identity in every-day consumption and waste practices. Environ. Values 2017, 26, 733-755. [CrossRef]

48. Groves, C.; Henwood, K.; Shirani, F.; Butler, C.; Parkhill, K.; Pidgeon, N. Invested in unsustainability? On the psychosocial patterning of engagement in practices. Environ. Values 2015, 25, 309-328. [CrossRef]

49. Antikainen, M.; Lammi, M.; Paloheimo, H.; Rüppel, T.; Valkokari, K. Towards circular economy business models: Consumer acceptance of novel services. In Proceedings of the ISPIM Innovation Summit, Brisbane, Australia, 6-9 December 2015.

(C) 2018 by the authors. Licensee MDPI, Basel, Switzerland. This article is an open access article distributed under the terms and conditions of the Creative Commons Attribution (CC BY) license (http://creativecommons.org/licenses/by/4.0/). 